\title{
Systemic and regional hemodynamic effects of enalaprilat infusion in experimental normotensive sepsis
}

L. Rahal, A.G. Garrido, R.J. Cruz Jr.,

M. Rocha e Silva and L.F. Poli-de-Figueiredo
Divisão de Experimentação, Instituto do Coração, Faculdade de Medicina, Universidade de São Paulo, São Paulo, SP, Brasil

\section{Correspondence \\ A.G. Garrido \\ Rua Pintassilgo, 516/188 \\ 04514-032 São Paulo, SP \\ Brasil \\ Fax: +55-11-3085-7887 \\ E-mail: alejandragg@terra.com.br \\ Research supported by FAPESP \\ (No. 05/51176-5).}

Received October 27, 2005

Accepted June 28, 2006

\begin{abstract}
Angiotensin-converting enzyme inhibitors have been shown to improve splanchnic perfusion in distinct shock states. We hypothesized that enalaprilat potentiates the benefits of early fluid resuscitation in severe experimental sepsis, particularly in the splanchnic region. Anesthetized and mechanically ventilated mongrel dogs received an intravenous infusion of live Escherichia coli over a period of $30 \mathrm{~min}$. Thereafter, two interventions were performed: fluid infusion (normal saline, $32 \mathrm{~mL} / \mathrm{kg}$ over $30 \mathrm{~min})$ and enalaprilat infusion $\left(0.02 \mathrm{mg} \mathrm{kg}^{-1}\right.$ $\mathrm{min}^{-1}$ for $60 \mathrm{~min}$ ) in randomized groups. The following groups were studied: controls (fluid infusion, $\mathrm{N}=4$ ), E1 (enalaprilat infusion followed by fluid infusion, $\mathrm{N}=5$ ) and $\mathrm{E} 2$ (fluid infusion followed by enalaprilat infusion, $\mathrm{N}=5$ ). All animals were observed for a $120 \mathrm{~min}$ after bacterial infusion. Mean arterial pressure, cardiac output (CO), portal vein blood flow (PVBF), systemic and regional oxygen-derived variables, and lactate levels were measured. Rapid and progressive reductions in $\mathrm{CO}$ and $\mathrm{PVBF}$ were induced by the infusion of live bacteria, while minor changes were observed in mean arterial pressure. Systemic and regional territories showed a significant increase in oxygen extraction and lactate levels. Widening venous-arterial and portal-arterial $\mathrm{pCO}_{2}$ gradients were also detected. Fluid replacement promoted transient benefits in $\mathrm{CO}$ and PVBF. Enalaprilat after fluid resuscitation did not affect systemic or regional hemodynamic variables. We conclude that in this model of normotensive sepsis inhibition of angiotensin-converting enzyme did not interfere with the course of systemic or regional hemodynamic and oxygen-derived variables.
\end{abstract}

\section{Introduction}

Despite major improvements in the management of critically ill patients and considerable knowledge of sepsis pathophysiology, the mortality in the sepsis setting remains unacceptably high, especially when
Key words

- Cardiac output

- Escherichia coli

- Enalaprilat

- Portal vein blood flow

- Septic shock

.................... 
It has been widely accepted that the splanchnic region, particularly the gut mucosa, is highly vulnerable to reductions in oxygen supply and prone to early injury in the course of shock states and sepsis (4-9). Incomplete splanchnic resuscitation with persistent gut hypoxia or ischemia, and reperfusion injury are possible factors contributing to gastrointestinal tract barrier dysfunction, which may also contribute to the translocation of microorganisms and cytokines into the circulation $(4,10)$. These alterations have been implicated in the perpetuation and amplification of the systemic inflammatory response and in the development of multiple organ failure $(1,2,4,10,11)$.

While fluid replacement has been considered essential to restore tissue oxygen transport and to prevent subsequent cardiovascular deterioration of severe sepsis to a septic shock state (1-3), the disparity between systemic and regional variables has been well demonstrated $(6,8,12-14)$. Recently, in an experimental model of hypodynamic septic shock induced by intravenous injection of live Escherichia coli, we found that the early crystalloid infusion resulted in partial and transient benefits, essentially during fluid infusion, which were especially poor in the splanchnic bed (13). These findings suggest significant early capillary leakage with extravascular redistribution of the crystalloid administered, and indicate that monitoring the gastrointestinal territory is probably desirable to improve splanchnic resuscitation.

Capillary leakage is frequently associated with inflammatory states such as trauma, shock, and sepsis $(15,16)$. This phenomenon appears to be related to the increased release of several vasoactive mediators. Angiotensin II has been implicated as a possible mediator of microvascular dysfunction in multiple organ dysfunction syndrome $(17,18)$. Additionally, animal and human data suggest a primary role of angiotensin II in the etiology of selective gut hypoperfusion after resusci- tation from shock states $(19,20)$. In animals, angiotensin-converting enzyme (ACE) inhibitors have been shown to improve splanchnic perfusion (21-24), to decrease bacterial translocation (25) and to improve survival (26) in various types of shock. Moreover, enalaprilat enhanced gut perfusion measured by gastric tonometry in critically injured trauma patients (27) and improved endothelial function in septic patients (28).

Since the production of angiotensin II has been reported to increase significantly after a septic insult, we determined the systemic and regional hemodynamic effects of enalaprilat, an inhibitor of ACE, in experimental normotensive sepsis. We hypothesized that enalaprilat infusion should improve the hemodynamic effects of fluid resuscitation.

\section{Material and Methods}

The study was approved by the Animal Care and Use Committee of the University of São Paulo Medical School and was conducted in compliance with the guidelines of the National Regulations for the Care and Use of Laboratory Animals.

\section{Animal preparation}

Fourteen healthy male mongrel dogs weighing 15-20 kg were fasted for $12 \mathrm{~h}$ before the study, with free access to water. Anesthesia was induced with an intravenous injection of $0.1 \mathrm{mg} / \mathrm{kg}$ morphine sulfate followed by $10 \mathrm{mg} / \mathrm{kg}$ ketamine chlorhydrate, $10 \mathrm{mg} / \mathrm{kg}$ diazepam, and $0.1 \mathrm{mg} / \mathrm{kg}$ pancuronium. Anesthesia was maintained by continuous infusion of ketamine chlorhydrate, $12 \mathrm{mg} \mathrm{kg}^{-1} \mathrm{~h}^{-1}$, and fentanyl sulfate, $10 \mu \mathrm{g}$ $\mathrm{kg}^{-1} \mathrm{~h}^{-1}$. A cuffed endotracheal tube was placed in the trachea to allow mechanical ventilation at an $\mathrm{FiO}_{2}$ of 0.21 and tidal volume of $10 \mathrm{~mL} / \mathrm{kg}$ (Servo ${ }^{\mathrm{i}}$, Siemens ventilator system, V. 1.3; Siemens, Solna, Sweden). Respiratory rate was adjusted to main- 
tain $\mathrm{PaCO}_{2}$ at $40 \pm 5 \mathrm{mmHg}$. A urinary bladder catheter was placed for urinary drainage and measurement of urinary output. During surgical procedure, a heating pad was used to maintain normothermia and the animals received $0.9 \%$ saline solution at 20 $\mathrm{mL} \mathrm{kg}^{-1} \mathrm{~h}^{-1}$ to compensate for fluid losses related to the surgical procedures.

The right common femoral artery was dissected and cannulated with a polyethylene catheter (PE240) to measure mean arterial pressure (MAP) in the abdominal aorta and to collect arterial blood samples for blood gas and lactate analysis. A PE240 catheter was introduced through the right common femoral vein for fluid replacement and for bacterial and enalaprilat infusion. Anesthetic agents were administrated through the left common femoral vein.

A balloon-tipped catheter (7-Fr; Baxter Health Care Co., Irvine, CA, USA) was inserted into the pulmonary artery through the right external jugular vein under guidance of pressure waves, as determined by a multichannel monitor system. This catheter was connected to a cardiac computer (Vigilance ${ }^{\mathrm{TM}}$; Baxter Edwards Critical Care, Irvine, CA, USA) to measure cardiac output using 3-mL bolus injections of isotonic saline at $20^{\circ} \mathrm{C}$. All catheters were connected to disposable pressure transducers (Transpac Disposable Transducer; Abbott, Chicago, IL, USA) and to a computerized multichannel system for biological data acquisition (Acknowledge $^{\circledR}$ III MP 100 WSW; Biopac Systems, Inc., Goleta, CA, USA).

Splenectomy was performed through a midline laparotomy to prevent splenocontraction and autotransfusion of erythrocytes. An ultrasonic flow probe (Transonic Systems, Inc., Ithaca, NY, USA) was placed around the portal vein for transit time flow measurement (T206 transonic volume flowmeter, Transonic Systems). A P240 catheter was threaded into the portal system via the splenic vein for portal vein blood sampling. The abdominal cavity was then carefully closed.
The animals were allowed to recover for 30 min before the experimental protocol was started and the infusion of $0.9 \%$ saline was reduced to $1 \mathrm{~mL} \mathrm{~kg}^{-1} \mathrm{~h}^{-1}$.

\section{Bacterial preparation}

A strain of E. coli $\mathrm{O} 55$ provided by Department of Bacteriology of Adolfo Lutz Institute, São Paulo, SP, Brazil, originating from the stool of a patient with gastrointestinal sepsis, was used in this study. Briefly, according to previous studies $(13,14)$, the bacteria were stored in a preservation medium at room temperature, activated in trypticase soy broth, plated onto trypticase soy agar, and incubated at $37^{\circ} \mathrm{C}$ for $24 \mathrm{~h}$. Aliquots were then suspended in sterile saline. The bacterial suspension was estimated turbidimetrically by comparing the newly grown bacterial suspension to known standards by spectrophotometry at $625 \mathrm{~nm}$, in order to obtain a culture of desired bacterial density. The same suspension was subsequently quantified by plating successive 10fold dilutions onto trypticase soy agar plates and scoring visible colonies after $24 \mathrm{~h}$ of incubation at $37^{\circ} \mathrm{C}$. The target dose, as calculated by the methods outlined above, was $3 \times 10^{9}$ cells $/ \mathrm{mL}$ or $0.6 \times 10^{10} \mathrm{cfu} / \mathrm{mL}$. Then, $1.2 \times 10^{10} \mathrm{cfu} / \mathrm{kg}$ body weight was used to induce sepsis.

\section{Drug}

Enalaprilat maleate (Sigma-Aldrich, St. Louis, MO, USA) was diluted in $0.9 \%$ saline at the concentration of $0.1 \mathrm{mg} / \mathrm{mL}$ and infused continuously for $60 \mathrm{~min}$ at the rate of $0.02 \mathrm{mg}$ $\mathrm{kg}^{-1} \mathrm{~min}^{-1}$, according to previous experimental protocols (24) using a peristaltic infusion pump (Peristaltic Pump 66, Harvard Apparatus, South Natick, MA, USA).

\section{Experimental protocol (Figure 1)}

After stabilization, baseline (T0) meas- 
urements were obtained. Infusion of $E$. coli at the dose of $1.2 \times 10^{10} \mathrm{cfu} / \mathrm{kg}$ was started and maintained for $30 \mathrm{~min}$ in all groups (T30). The animals were randomized into three groups: control (CT, $\mathrm{N}=4), 0.9 \%$ saline, $32 \mathrm{~mL} / \mathrm{kg}$ over $30 \mathrm{~min}$; enalaprilat (E1, $\mathrm{N}=5$ ), $0.02 \mathrm{mg} \mathrm{kg}^{-1} \mathrm{~min}^{-1}$ for $60 \mathrm{~min}$ followed by $32 \mathrm{~mL} / \mathrm{kg} 0.9 \%$ saline for 30 $\mathrm{min}$; $\mathrm{E} 2(\mathrm{~N}=5), 32 \mathrm{~mL} / \mathrm{kg} 0.9 \%$ saline over $30 \mathrm{~min}$ followed by enalaprilat, $0.02 \mathrm{mg} \mathrm{kg}^{-}$ ${ }^{1} \mathrm{~min}^{-1}$ for $60 \mathrm{~min}$. The animals were observed while receiving a continuous infusion of $0.9 \%$ saline at the dose of $1 \mathrm{~mL} \mathrm{~kg}^{-1}$ $\mathrm{h}^{-1}$ for 120 min after bacterial infusion (T150). At the end of the experimental protocol, the animals were euthanized with a pentobarbital overdose followed by an injection of hypertonic potassium chloride.

\section{Data collection and analysis}

Mean systemic and pulmonary arterial pressures and portal vein blood flow were recorded continuously. Cardiac output was determined using a thermodilution technique and was expressed as cardiac index according to the estimated body surface area. Each determination was the arithmetic mean of three consecutive measurements when their differences did not exceed $10 \%$. Central venous blood temperature was recorded from the thermistor in the pulmonary artery catheter. No measure was taken to keep the body temperature constant after the induction of septic shock.

The following $\mathrm{pCO}_{2}$ gradients were calculated: $\mathrm{D}(\mathrm{v}-\mathrm{a}) \mathrm{pCO}_{2}$, as the difference be-
Figure 1. Schematic presentation of the experimental protocol. Blood samples were collected and systemic and regional hemodynamic were measured at each time indicated on the x-axis (T0-T150). For group definitions, see legend to Figure 2.

Figure 2. Mean arterial pressure during the experimental protocol. Data are reported as mean \pm SEM. CT (control, $N=4)=$ fluid resuscitation (T30-T60) group; E1 $(\mathrm{N}=5)$ = enalaprilat (T30-T90) + fluid resuscitation (T90-T120) group; E2 $(\mathrm{N}=5)=$ fluid resuscitation (T30-T60) + enalaprilat (T60-T120) group. ${ }^{\mathrm{a} C T}, \mathrm{P}<0.05$ vs TO; ${ }^{\mathrm{b}} \mathrm{E} 1, \mathrm{P}<$ 0.05 vs T0; ${ }^{\mathrm{C}} \mathrm{E} 2, \mathrm{P}<0.05$ vs T0; $\mathrm{dP}<0.05 \mathrm{CT} v s \mathrm{E} 1$; ${ }^{\mathrm{P}}<0.05$ E1 vs E2 (ANOVA).
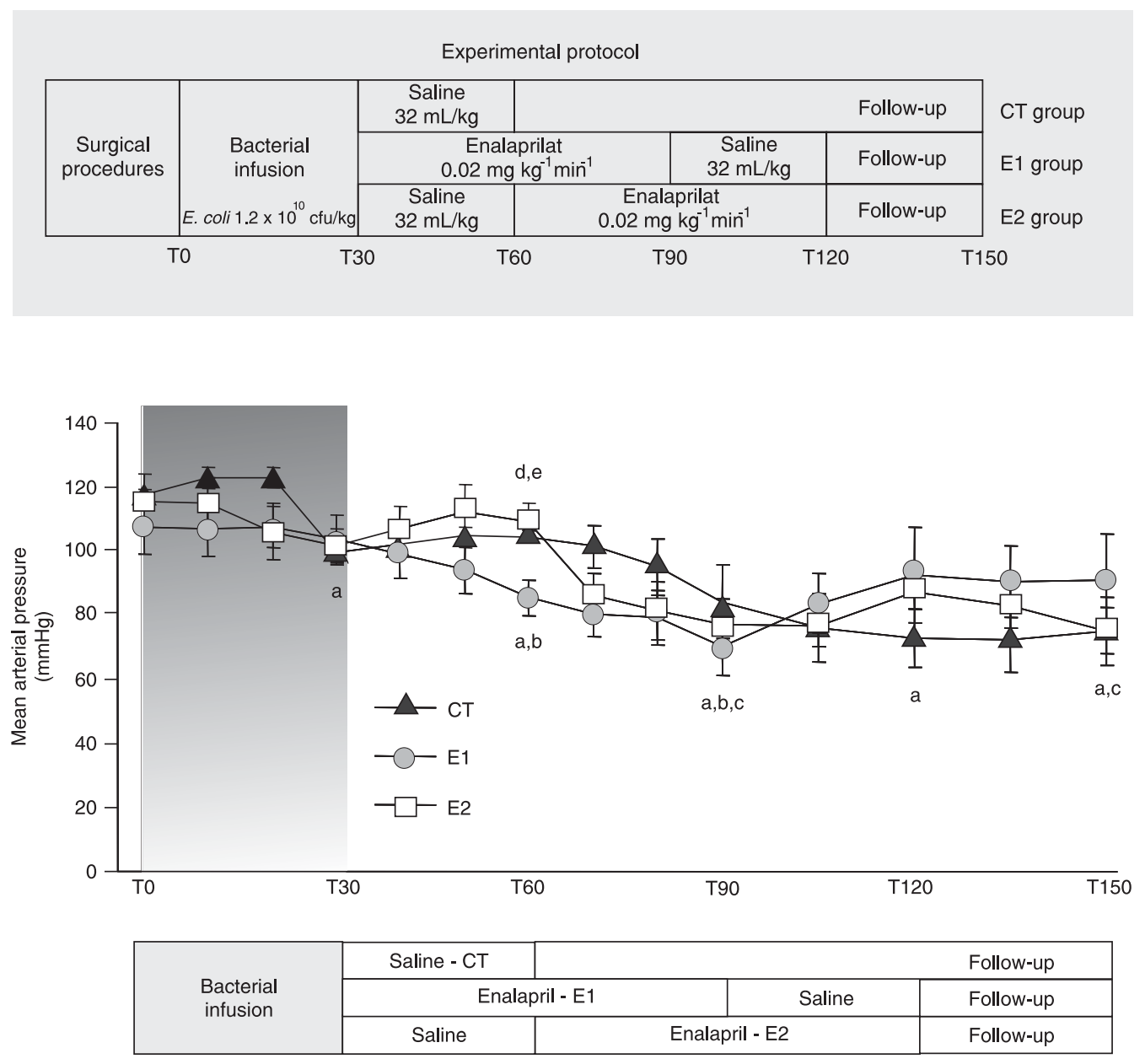
tween mixed venous $\mathrm{pCO}_{2}$ and arterial $\mathrm{pCO}_{2}$, and $\mathrm{D}(\mathrm{p}-\mathrm{a}) \mathrm{pCO}_{2}$, as the difference between portal vein $\mathrm{pCO}_{2}$ and arterial $\mathrm{pCO}_{2}$.

Blood gases, hemoglobin, hematocrit, and blood lactate levels were obtained from arterial, portal and mixed venous samples at baseline (T0) and at 30, 60, 90, 120, and 150 min after the initiation of bacterial infusion. All blood samples were analyzed with a Stat Profile Ultra Analyzer (Nova Biomedical, Waltham, MA, USA). The arterial oxygen content, mixed venous oxygen content, portal oxygen content, systemic oxygen delivery, mesenteric oxygen delivery, systemic oxygen extraction ratio, mesenteric oxygen extraction ratio, systemic oxygen consumption $\left(\mathrm{sVO}_{2}\right)$, mesenteric oxygen consumption, and arteriovenous and arterioportal oxygen content difference were calculated using standard formulae.

\section{Statistical analysis}

Data are reported as means \pm SEM. Statistical analysis was performed using the Statistical Package for the Social Sciences for Windows (version 6.0, SPSS Inc., Chicago, IL, USA). Differences between groups were analyzed using repeated measure analysis of variance and the post hoc Tukey test. The level of significance was set at $\mathrm{P}<0.05$.

\section{Results}

\section{Effects of live Escherichia coli infusion}

The infusion of live bacteria promoted a hypodynamic sepsis state in all animals. Although minor changes in MAP were detected (Figure 2), marked decreases in cardiac output and portal blood flow were observed (Figure 3), while a progressive increase in systemic and mesenteric oxygen extraction rate and widening of $\mathrm{D}(\mathrm{v}-\mathrm{a}) \mathrm{pCO}_{2}$ and $\mathrm{D}(\mathrm{p}-\mathrm{a}) \mathrm{pCO}_{2}$ gradients occurred throughout the experiment (Tables 1 and 2, Figure
4). Metabolic acidosis and gradual increases in arterial and portal lactate levels began after bacterial infusion (Tables 1 and 2). The hemoglobin levels increased in all groups after bacterial infusion (Table 1).

\section{Effects of fluid replacement}

Fluid replacement immediately after bacterial infusion (CT and E2 groups) promoted marked and transient increases in cardiac output and portal vein blood flow (Figure 3 ). These alterations were accompanied by shortlasting increases in oxygen delivery and mixed venous oxygen saturation at the systemic level (Table 1), while brief decreases in $\mathrm{D}(\mathrm{p}-\mathrm{a}) \mathrm{pCO}_{2}$ and mesenteric oxygen extraction were detected at the regional level
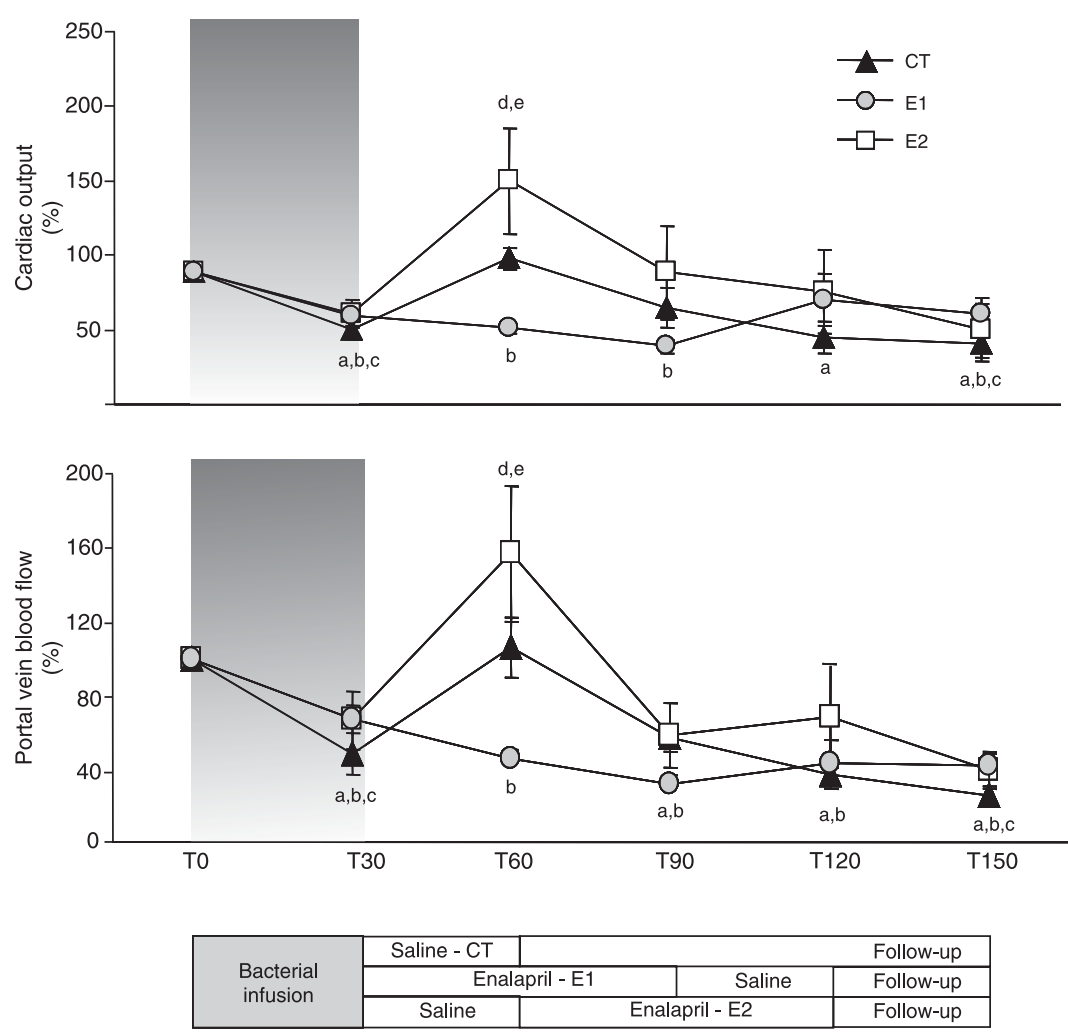

Figure 3. Cardiac output (\%, mean \pm SEM) and portal vein blood flow $(\%$, mean \pm SEM) during the experimental protocol. $\mathrm{CT}$ (control, $\mathrm{N}=4)$ = fluid resuscitation $(\mathrm{T} 30-\mathrm{T} 60)$ group; $\mathrm{E} 1(\mathrm{~N}=5)=$ enalaprilat $(\mathrm{T} 30-\mathrm{T} 90)+$ fluid resuscitation $(\mathrm{T} 90-\mathrm{T} 120)$ group; $\mathrm{E2}(\mathrm{N}=5)=$ fluid resuscitation (T30-T60) + enalaprilat (T60-T120) group. ${ }^{\mathrm{a}} \mathrm{CT}, \mathrm{P}<0.05$ vs $\mathrm{TO}$; ${ }^{\mathrm{b}} \mathrm{E} 1, \mathrm{P}<0.05$ vs T0; ${ }^{\mathrm{CE}} 2, \mathrm{P}<0.05$ vs T0; ${ }^{\mathrm{d} P}<0.05 \mathrm{CT}$ vs E1; ${ }^{\mathrm{eP}}<0.05 \mathrm{E} 1$ vs $\mathrm{E} 2$ (ANOVA). 
(Figure 4, Table 2). The effects of fluid replacement on blood flow after 60 min of enalaprilat infusion (E1 group) were less evident (Figure 3). Slight and transient decreases in hemoglobin levels were observed after fluid infusion in all groups (Table 1). No differences in urinary output were detected between groups $(\mathrm{CT}=3.9 \pm 2.32, \mathrm{E} 1=4.42 \pm 2.15$, and $\left.\mathrm{E} 2=4.35 \pm 0.96 \mathrm{~mL} \mathrm{~kg}^{-1} \mathrm{~h}^{-1}\right)$.

\section{Effects of enalaprilat infusion}

Enalaprilat infusion after fluid resuscita- tion (E2 group) did not promote significant changes in systemic hemodynamic or systemic oxygen-derived variables. The absence of fluid expansion was associated with no systemic or regional benefits during enalaprilat infusion in the E1 group, as shown by the significantly lower cardiac output, systemic oxygen delivery and mixed venous oxygen saturation, and lower portal vein blood flow, mesenteric oxygen delivery and portal vein oxygen saturation (Figure 3 , Tables 1 and 2) than in both groups that received fluids after the bacterial challenge.

Table 1. Systemic oxygen-derived variables for all groups.

\begin{tabular}{|c|c|c|c|c|c|c|}
\hline & TO & Т30 & \multirow[t]{2}{*}{ T60 } & \multirow[t]{2}{*}{ T90 } & \multirow[t]{2}{*}{ T120 } & \multirow[t]{2}{*}{ T150 } \\
\hline & \multicolumn{2}{|c|}{ Bacterial infusion } & & & & \\
\hline \multicolumn{7}{|c|}{$\mathrm{sDO}_{2}(\mathrm{~mL} / \mathrm{min})$} \\
\hline CT & $475 \pm 28.1$ & $329 \pm 50.8^{a}$ & $481 \pm 57$ & $363 \pm 68.8$ & $268 \pm 59.1^{a}$ & $251 \pm 59.6^{a}$ \\
\hline E1 & $490 \pm 88.9$ & $373 \pm 91.5^{a}$ & $328 \pm 69.6^{a}$ & $259 \pm 66.8^{a}$ & $349 \pm 103.8$ & $333 \pm 179.7^{a}$ \\
\hline E2 & $322 \pm 18.7^{c}$ & $248 \pm 35.9^{a}$ & $423 \pm 84.2$ & $284 \pm 177.8$ & $269 \pm 93.1$ & $188 \pm 73.7$ \\
\hline \multicolumn{7}{|c|}{$\mathrm{sVO}_{2}(\mathrm{~mL} / \mathrm{min})$} \\
\hline CT & $76.4 \pm 10.2$ & $67.8 \pm 12.7$ & $73.3 \pm 8.2$ & $91.7 \pm 12.5$ & $79.4 \pm 7.5$ & $88.9 \pm 17.4$ \\
\hline E1 & $99.5 \pm 20.5$ & $73.3 \pm 11.8$ & $80.9 \pm 12.2$ & $82.9 \pm 10.8$ & $82.3 \pm 17.4$ & $96.5 \pm 18.1$ \\
\hline E2 & $55.3 \pm 10.5$ & $56.5 \pm 7.7$ & $47.9 \pm 14.3$ & $70.8 \pm 14.3$ & $76.1 \pm 17.3$ & $67.7 \pm 14.2$ \\
\hline \multicolumn{7}{|c|}{$\mathrm{sO}_{2} \mathrm{ER}(\%)$} \\
\hline CT & $16.1 \pm 1.0$ & $22.4 \pm 2.8^{a}$ & $15.9 \pm 2.3$ & $35.5 \pm 1.9^{a}$ & $43.6 \pm 3.2^{\mathrm{a}}$ & $50.1 \pm 4.1^{\mathrm{a}}$ \\
\hline E1 & $20.0 \pm 1.6$ & $39.1 \pm 2.9^{a}$ & $25.3 \pm 2.9^{b, d}$ & $36.1 \pm 4.5^{a}$ & $27.2 \pm 5.3$ & $30.7 \pm 3.0^{\mathrm{a}}$ \\
\hline E2 & $16.8 \pm 3.4$ & $22.3 \pm 3.3^{a}$ & $12.7 \pm 2.8^{a}$ & $27.0 \pm 3.6^{a}$ & $31.6 \pm 4.2^{\mathrm{a}}$ & $42.6 \pm 7.4^{a}$ \\
\hline \multicolumn{7}{|c|}{$\mathrm{SvO}_{2}(\%)$} \\
\hline CT & $84.1 \pm 1.1$ & $78.5 \pm 3.0$ & $85.2 \pm 2.1$ & $70.9 \pm 2.9^{a}$ & $63.0 \pm 1.8^{\mathrm{a}}$ & $56.8 \pm 2.8^{a}$ \\
\hline E1 & $78.3 \pm 1.8$ & $73.4 \pm 3.1$ & $72.0 \pm 3.3^{b, d}$ & $60.6 \pm 5.1^{a}$ & $68.7 \pm 5.5$ & $66.0 \pm 4.1^{\mathrm{a}}$ \\
\hline E2 & $81.5 \pm 4.3$ & $76.1 \pm 4.1^{\mathrm{a}}$ & $82.9 \pm 3.5$ & $69.5 \pm 5.2^{\mathrm{a}}$ & $64.5 \pm 3.2^{\mathrm{a}}$ & $53.3 \pm 8.2^{\mathrm{a}}$ \\
\hline \multicolumn{7}{|c|}{$\mathrm{AL}(\mathrm{mmol} / \mathrm{L})$} \\
\hline CT & $0.4 \pm 0.1$ & $0.4 \pm 0.2^{b, c}$ & $1.5 \pm 0.3^{\mathrm{a}, \mathrm{b}}$ & $2.4 \pm 0.7^{a}$ & $3.6 \pm 1.0^{\mathrm{a}, \mathrm{c}}$ & $4.1 \pm 1.4^{a}$ \\
\hline E1 & $0.9 \pm 0.2$ & $1.6 \pm 0.2^{\mathrm{a}}$ & $3.0 \pm 0.3^{\mathrm{a}, \mathrm{d}}$ & $3.4 \pm 0.1^{a, d}$ & $2.9 \pm 0.3^{a}$ & $2.5 \pm 0.3^{a}$ \\
\hline E2 & $1.2 \pm 0.1$ & $1.5 \pm 0.1$ & $1.5 \pm 0.1$ & $2.4 \pm 0.3^{a}$ & $2.7 \pm 0.4^{a}$ & $3.5 \pm 0.8^{a}$ \\
\hline \multicolumn{7}{|c|}{ Arterial $\mathrm{pH}$} \\
\hline CT & $7.36 \pm 0.02$ & $7.35 \pm 0.01$ & $7.31 \pm 0.01^{a}$ & $7.31 \pm 0.01^{a, b}$ & $7.27 \pm 0.02^{a}$ & $7.23 \pm 0.04^{a}$ \\
\hline E1 & $7.32 \pm 0.01$ & $7.31 \pm 0.01$ & $7.30 \pm 0.01$ & $7.26 \pm 0.01^{a}$ & $7.22 \pm 0.02^{a}$ & $7.24 \pm 0.02^{a}$ \\
\hline E2 & $7.34 \pm 0.02$ & $7.33 \pm 0.02$ & $7.29 \pm 0.04^{a}$ & $7.26 \pm 0.06^{a}$ & $7.24 \pm 0.05^{a}$ & $7.20 \pm 0.06^{a}$ \\
\hline \multicolumn{7}{|c|}{$\mathrm{Hb}(\mathrm{mg} / \mathrm{dL})$} \\
\hline CT & $12.6 \pm 0.8$ & $14.1 \pm 0.9^{a}$ & $11.6 \pm 0.8^{a}$ & $12.7 \pm 0.7$ & $12.6 \pm 0.9$ & $12.8 \pm 0.8$ \\
\hline E1 & $12.9 \pm 0.9$ & $13.6 \pm 0.9$ & $13.8 \pm 1.0^{a}$ & $13.6 \pm 1.0$ & $11.7 \pm 0.9$ & $12.3 \pm 1.2$ \\
\hline E2 & $14.2 \pm 0.6$ & $15.0 \pm 0.7^{a}$ & $12.2 \pm 0.9^{a}$ & $13.6 \pm 0.6$ & $13.9 \pm 0.6$ & $14.4 \pm 0.7$ \\
\hline
\end{tabular}

Data are reported as means $\pm \mathrm{SEM} . \mathrm{sDO}_{2}=$ systemic oxygen delivery, $\mathrm{sVO}_{2}$ : systemic oxygen consumption; $\mathrm{sO}_{2} \mathrm{ER}=$ systemic oxygen extraction rate; $\mathrm{SvO}_{2}=$ mixed venous oxygen saturation; $\mathrm{AL}=$ arterial lactate; $\mathrm{Hb}=$ hemoglobin; $\mathrm{CT}($ control, $\mathrm{N}=4)=$ fluid resuscitation group (T30-T60); E1 $(\mathrm{N}=5)$ = enalaprilat $(\mathrm{T} 30-\mathrm{T} 90)$ + fluid resuscitation $(\mathrm{T} 90-\mathrm{T} 120)$ group; $\mathrm{E} 2(\mathrm{~N}=5)$ = fluid resuscitation $(\mathrm{T} 30-\mathrm{T} 60)+$ enalaprilat (T60-T120) group.

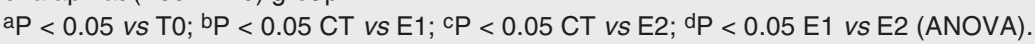


Table 2. Regional oxygen-derived variables for all groups.

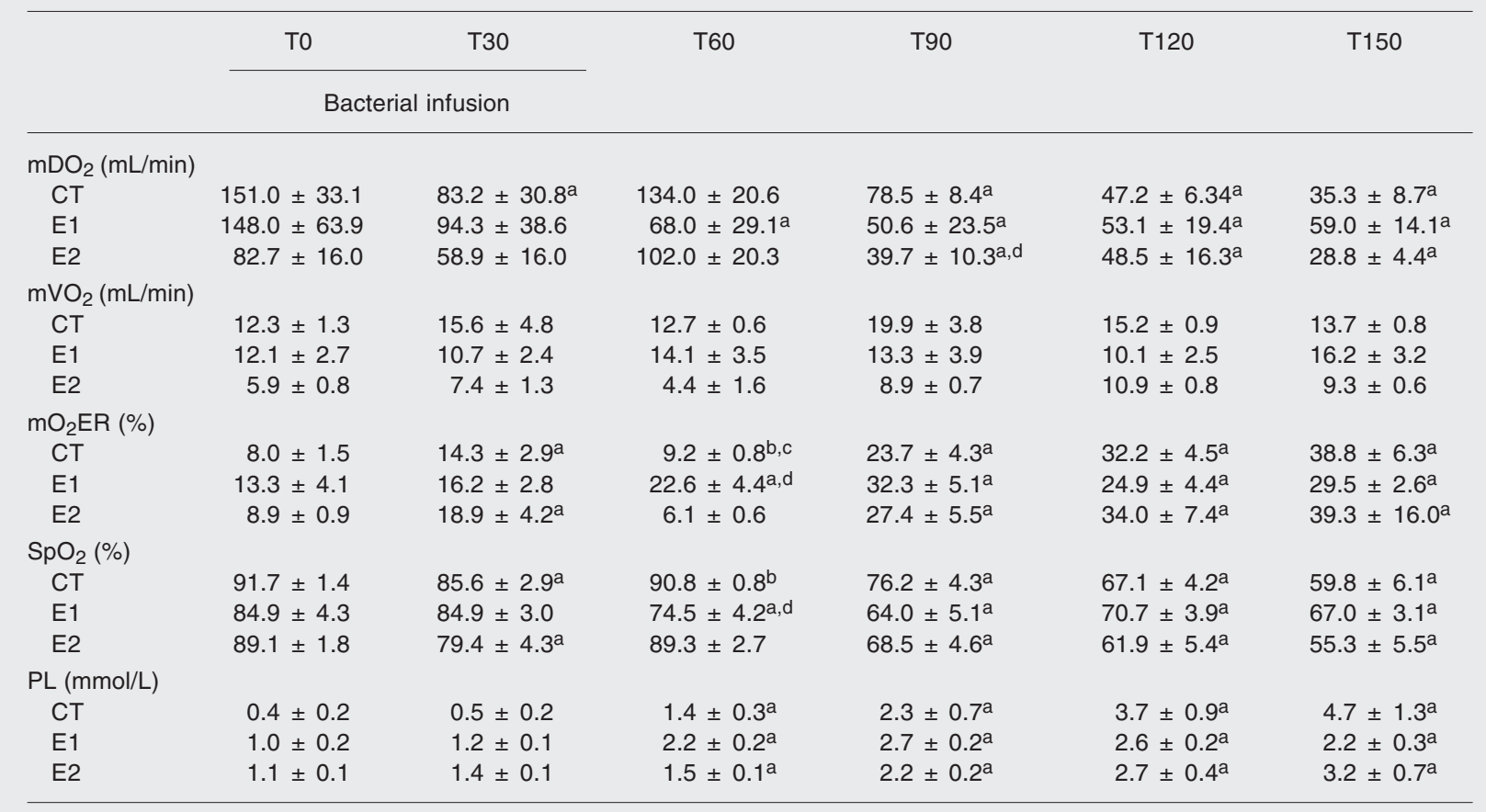

Data are reported as means $\pm \mathrm{SEM} . \mathrm{mDO}_{2}=$ mesenteric oxygen delivery; $\mathrm{mVO}_{2}=$ mesenteric oxygen consumption; $\mathrm{mO}_{2} \mathrm{ER}=$ mesenteric oxygen extraction rate; $\mathrm{SpO}_{2}=$ portal vein oxygen saturation; $\mathrm{PL}=$ portal vein lactate; $\mathrm{CT}$ (control, $\left.\mathrm{N}=4\right)=$ fluid resuscitation $(\mathrm{T} 30-\mathrm{T} 60)$ group; $\mathrm{E} 1(\mathrm{~N}=5)$ = enalaprilat $(\mathrm{T} 30-\mathrm{T} 90)+$ fluid resuscitation $(\mathrm{T} 90-\mathrm{T} 120)$ group; $\mathrm{E2}(\mathrm{N}=5)$ = fluid resuscitation $(\mathrm{T} 30-\mathrm{T} 60)+$ enalaprilat (T60-T120) group.

aP $<0.05$ vs T0; ${ }^{\text {bP }}<0.05 \mathrm{CT}$ vs E1; ${ }^{\mathrm{CP}}<0.05 \mathrm{CT}$ vs E2; ${ }^{\mathrm{d} P}<0.05 \mathrm{E} 1$ vs $\mathrm{E} 2$ (ANOVA).

Figure 4. $\mathrm{D}(\mathrm{v}-\mathrm{a}) \mathrm{pCO}_{2}$ gradient $(\mathrm{mmHg}$, mean $\pm \mathrm{SEM})$ and $\mathrm{D}(\mathrm{p}-\mathrm{a}) \mathrm{pCO}_{2}$ gradient $(\mathrm{mmHg}$, mean $\pm \mathrm{SEM})$ during the experimental protocol. CT (control, $N=4)$ = fluid resuscitation $(\mathrm{T} 30-\mathrm{T} 60)$ group; $\mathrm{E} 1(\mathrm{~N}=5)=$ enalaprilat (T30-T90) + fluid resuscitation (T90-T120) group; E2 $(\mathrm{N}=5)$ = fluid resuscitation $(\mathrm{T} 30-\mathrm{T} 60)+$ enalaprilat (T60-T120) group. $\mathrm{D}(\mathrm{v}-\mathrm{a}) \mathrm{pCO}_{2}=$ difference between mixed venous $\mathrm{pCO}_{2}$ and arterial $\mathrm{pCO}_{2} ; \mathrm{D}(\mathrm{p}-\mathrm{a}) \mathrm{pCO}_{2}=$ difference between portal vein $\mathrm{pCO}_{2}$ and arterial $\mathrm{pCO}_{2}$. ${ }^{\mathrm{a} C T}, \mathrm{P}<0.05$ vs T0; ${ }^{\mathrm{b}} \mathrm{E} 1, \mathrm{P}<0.05$ vs T0; ${ }^{\mathrm{C}} \mathrm{E} 2, \mathrm{P}<0.05$ vs T0; ${ }^{\mathrm{dP}}<0.05$ CT vs E1; ${ }^{\mathrm{P}}<0.05$ CT vs E2; ${ }^{\mathrm{f}}<<$ $0.05 \mathrm{E} 1$ vs E2 (ANOVA).
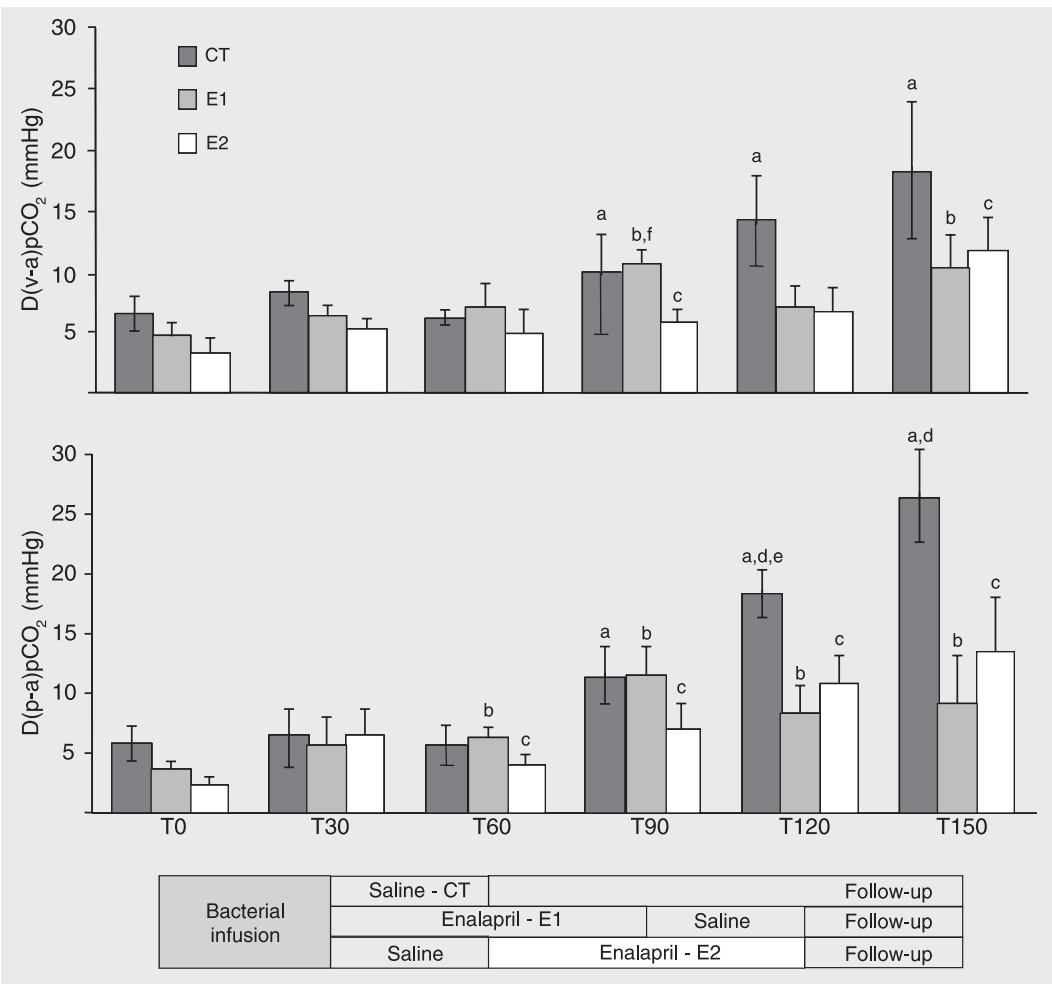
However, at the end of the experimental protocol, no significant differences could be detected between groups for any hemodynamic or oxygen-derived variables.

\section{Discussion}

Using an intravenous injection of live $E$. coli, we reproduced the hemodynamic and metabolic derangement observed in non-resuscitated hypodynamic sepsis. Those striking alterations were detected at both the systemic and regional levels. Early fluid replacement promoted marked but transient benefits which were unable to restore sepsisinduced perfusional deficits. Contrary to our expectation, enalaprilat infusion did not interfere with the course of hemodynamic and oxygen-derived variables either at the systemic or at the regional level when preceded by fluid resuscitation. The transient period of lower blood flow observed in E1 group (enalaprilat infusion before fluid administration) did not result in worse hemodynamic or oxygen-derived variables by the end of the experimental protocol. Thus, in spite of the severe hemodynamic derangement promoted by $E$. coli infusion, we did not observe significant undesirable effects of enalaprilat infusion in this model.

We evaluated the potential hemodynamic benefits of the ACE inhibitor enalaprilat during early fluid resuscitation in a hypodynamic sepsis model. However, all animals presented gradual cardiovascular deterioration without any significant difference between groups. These data contrast with findings of previous studies $(24,29)$. During hypotensive resuscitation from hemorrhagic shock in dogs, enalaprilat infusion increased cardiac index, stroke volume index, superior mesenteric artery flow, stroke work, and left ventricular power output without causing a hypotensive crisis (29). In other hemorrhage protocols applied to dogs, Wall et al. (24) also showed that enalaprilat infusion during resuscitation was associated with an increase in systemic, celiac and portal blood flow.

These divergent findings could be explained by several reasons. First, it is necessary to take into consideration the difference of pathophysiology in the two settings. While in septic shock there is an early microcirculatory dysfunction with high heterogeneity and irregular distribution of blood flow, in hemorrhagic shock these alterations are observed in later stages. Second, we need to consider that our fixed fluid replacement schedule promoted an incomplete resuscitation. However, even without differences between groups at the end of the experimental protocol, fluid resuscitation preceding enalaprilat infusion appeared to be safer. Third, our model was induced by infusion of a high load of live bacteria and promoted rapid cardiovascular disturbances, and possibly in this condition few interventions would lead to notorious benefits. Finally, there are few studies using enalaprilat infusion to improve splanchnic resuscitation in septic setting, and therefore the adequate dose needs to be defined, as well as the best drug to be used, i.e., an ACE inhibitor or a selective angiotensin II antagonist.

Moreover, the splanchnic perfusion disturbances in sepsis are also complicated by regional hypermetabolism, cytopathic hypoxia and microcirculatory disturbances. These factors may contribute to the discrepancy between the beneficial effects on systemic and even regional oxygen delivery and the lack of beneficial effects on intestinal perfusion. The opposite is also possible. In critically injured patients, enalaprilat infusion improved gut perfusion as measured by gastric tonometry without any change in systemic variables (27). The authors concluded that enalaprilat selectively improves intestinal perfusion (27). In a porcine burn/ endotoxemia model the angiotensin II receptor antagonist DuP753 improved mesenteric oxygen supply and significantly reduced mucosal injury and bacterial translocation (30). Unfortunately, we did not assess 
intestinal microcirculatory perfusion, morphologic changes or bacterial translocation.

The increase in hemoglobin levels in our splenectomized dogs after bacterial challenge suggested hypovolemia due to ongoing fluid losses, probably through increased microvascular permeability. Moreover, a brief period of hemodilution and flow improvement after fluid replacement suggest rapid extravascular redistribution of the infused fluid volume. These results were in accordance with our previous study (13). No changes were observed with enalaprilat infusion. Studies have isolated angiotensin II type 1 and type 2 receptor subtypes in several tissues, including endothelial cells and have suggested involvement in the modulation of vascular permeability (17). In septic patients, enalaprilat infusion reduced the release of soluble endothelial-derived substances into the circulating blood, which may indicate improved endothelial function (9). We can speculate that in our study the increase of bradykinin levels in the splanchnic bed related to inhibition of ACE may prevent the potential benefit of enalaprilat in increasing microvascular permeability. However, the specific action of enalaprilat on the endothelium remains to be elucidated.

Reduction of about $40 \%$ in cardiac output and in portal blood flow began immediately after the initiation of the bacterial infusion. The hemodynamic changes were accompanied by an increase in $\mathrm{D}(\mathrm{v}-\mathrm{a}) \mathrm{pCO}_{2}$, $\mathrm{D}(\mathrm{p}-\mathrm{a}) \mathrm{pCO}_{2}$, and systemic and mesenteric oxygen extraction throughout the experiment. Such alterations may have resulted from a combination of arterial and venous vasodilatation, hypovolemia and myocardial depression. Bacterial-induced alterations in peripheral vascular tone, leading to venous pooling of blood and reduced venous return, probably accounted for the immediate decrease in systemic and splanchnic blood flow (13). The more modest decrease in MAP $(\sim 15 \%)$ in comparison to the greater decrease in blood flow could be attributed to a complex combination of vasoconstriction and vasodilatation. These abnormalities demand vigorous fluid replacement and could explain the brief period of lower blood flow during enalaprilat infusion when the drug was administered without fluid replacement. The absence of a septic group without any intervention does not allow us to exclude a role of enalaprilat in this phenomenon. However, we could speculate that an incomplete fluid resuscitation resulted in poor benefits from the inhibitor of ACE administration in this model.

So far, the inhibitor of ACE has not been well investigated in septic situations, and longer term studies of sepsis are still lacking. However, there are substantial data that support the involvement of the angiotensin II in the pathophysiology of splanchnic perfusion disturbances and endothelial function abnormalities in shock states and many of them strongly suggest potential beneficial effects of the inhibitor of ACE in septic settings.

Our control group received fluid resuscitation with no other intervention. Our previous study (13) included a control group with no fluid, showing a sustained systemic and regional hypoperfusion. The rationale for using enalaprilat before fluid infusion was to determine if this procedure would protect the endothelium and potentiate the subsequent benefits from fluid infusion and to observe if it could cause harmful hypotension. Since fluid infusion is one of the first interventions in the treatment of septic patients, the use of enalaprilat following fluids could show a synergistic benefit.

There are limitations in our experimental model and protocol, as is also true for most models of sepsis and septic shock (31). Our model induced immediate hemodynamic disturbances. This behavior is seldom observed in clinical sepsis, although the present model may mimic the extreme clinical sepsis such as seen in meningococcemia, pneumococcal bacteremia in asplenic individuals, 
and Gram-negative bacteremia in the setting of profound granulocytopenia (31). This is a severe condition and few interventions might present benefits. We should also keep in mind that human sepsis has a time course that may be substantially longer than that of most experimental studies (31), which are conducted from a short-term perspective. Moreover, septic patients are not treated with a fixed volume or a fixed time of fluid challenge. However, despite the short period of fluid challenge, the amount of fluid used was the same as administered in the initial management of septic patient. Additionally, the absence of a septic group without any intervention did not allow us to show the natural course of hemodynamic variables in this model. Finally, this is a preliminary study with a small number of animals and a short follow-up period, and we did not assess gut mucosal microcirculation perfusion as measured by gas tonometry, nor did we determine the histological alterations. However, our results suggest that it is safe to administer enalaprilat in normotensive sepsis, especially after fluid replacement.

Within the limitations of our study protocol, we conclude that, in spite of the severe hemodynamic derangement promoted by $E$. coli infusion, enalaprilat infusion did not interfere with the course of systemic and regional hemodynamic and oxygen-derived consequences. The specific actions of this ACE inhibitor in sepsis require further studies.

\section{References}

1. Hollenberg SM, Ahrens TS, Annane D, Astiz ME, Chalfin DB, Dasta $\mathrm{JF}$, et al. Practice parameters for hemodynamic support of sepsis in adult patients: 2004 update. Crit Care Med 2004; 32: 1928-1948.

2. Reinhart K, Sakka SG, Meier-Hellmann A. Haemodynamic management of a patient with septic shock. Eur J Anaesthesiol 2000; 17: 617.

3. Rivers E, Nguyen B, Havstad S, Ressler J, Muzzin A, Knoblich B, et al. Early goal-directed therapy in the treatment of severe sepsis and septic shock. N Engl J Med 2001; 345: 1368-1377.

4. Pastores SM, Katz DP, Kvetan V. Splanchnic ischemia and gut mucosal injury in sepsis and the multiple organ dysfunction syndrome. Am J Gastroenterol 1996; 91: 1697-1710.

5. Fink MP. Gastrointestinal mucosal injury in experimental models of shock, trauma, and sepsis. Crit Care Med 1991; 19: 627-641.

6. Hamilton-Davies C, Mythen MG, Salmon JB, Jacobson D, Shukla A, Webb AR. Comparison of commonly used clinical indicators of hypovolaemia with gastrointestinal tonometry. Intensive Care Med 1997; 23: 276-281.

7. Knichwitz G, Rotker J, Mollhoff T, Richter KD, Brussel T. Continuous intramucosal $\mathrm{PCO}_{2}$ measurement allows the early detection of intestinal malperfusion. Crit Care Med 1998; 26: 1550-1557.

8. Cruz RJ, Yada-Langui MM, Poli de Figueiredo LF, Rocha e Silva M. Effects of hemorrhage and rapid fluid resuscitation on splanchnic blood flow and gastrointestinal mucosal perfusion evaluated by gas tonometry. Arq Bras Cir Digest 2002; 15: 74-78.

9. Boldt J, Papsdorf M, Kumle B, Piper S, Hempelmann G. Influence of angiotensin-converting enzyme inhibitor enalaprilat on endothelialderived substances in the critically ill. Crit Care Med 1998; 26: 16631670.

10. Doig CJ, Sutherland LR, Sandham JD, Fick GH, Verhoef M, Meddings JB. Increased intestinal permeability is associated with the development of multiple organ dysfunction syndrome in critically ill ICU patients. Am J Respir Crit Care Med 1998; 158: 444-451.

11. Ding J, Magnotti LJ, Huang Q, Xu DZ, Condon MR, Deitch EA. Hypoxia combined with Escherichia coli produces irreversible gut mucosal injury characterized by increased intestinal cytokine production and DNA degradation. Shock 2001; 16: 189-195.

12. Whitworth PW, Cryer HM, Garrison RN, Baumgarten TE, Harris PD. Hypoperfusion of the intestinal microcirculation without decreased cardiac output during live Escherichia coli sepsis in rats. Circ Shock 1989; 27: 111-122.

13. Garrido AG, Poli de Figueiredo LF, Cruz RJ Jr, Silva E, Rocha e Silva M. Short-lasting systemic and regional benefits of early crystalloid infusion after intravenous inoculation of dogs with live Escherichia coli. Braz J Med Biol Res 2005; 38: 873-884.

14. Lagoa CE, de Figueiredo LF, Cruz RJ Jr, Silva E, Rocha e Silva M. Effects of volume resuscitation on splanchnic perfusion in canine model of severe sepsis induced by live Escherichia coli infusion. Crit Care 2004; 8: R221-R228.

15. Michel CC, Curry FE. Microvascular permeability. Physiol Rev 1999; 79: 703-761.

16. Reilly PM, Bulkley GB. Vasoactive mediators and splanchnic perfusion. Crit Care Med 1993; 21: S55-S68.

17. Victorino GP, Newton CR, Curran B. Effect of angiotensin II on microvascular permeability. J Surg Res 2002; 104: 77-81.

18. Hilton JG, Marullo DS. Trauma induced increases in plasma vasopressin and angiotensin II. Life Sci 1987; 41: 2195-2200.

19. McNeill JR, Stark RD, Greenway CV. Intestinal vasoconstriction after hemorrhage: roles of vasopressin and angiotensin. Am J Physiol 1970; 219: 1342-1347.

20. Ackland G, Grocott MP, Mythen MG. Understanding gastrointestinal perfusion in critical care: so near, and yet so far. Crit Care 2000; 4: 269-281.

21. Bailey RW, Bulkley GB, Hamilton SR, Morris JB, Haglund UH. 
Protection of the small intestine from nonocclusive mesenteric ischemic injury due to cardiogenic shock. Am J Surg 1987; 153: 108116.

22. Suvannapura A, Levens NR. Local control of mesenteric blood flow by the renin-angiotensin system. Am J Physiol 1988; 255: G267G274.

23. Aneman A, Svensson M, Broome M, Biber B, Petterson A, Fandriks L. Specific angiotensin II receptor blockage improves intestinal perfusion during graded hypovolemia in pigs. Crit Care Med 2000; 28: 818-823.

24. Wall P, Buising C, Henderson L, Freeman B, Vincent R, Albright J, et al. Enalaprilat improves systemic and mesenteric blood flow during resuscitation from hemorrhagic shock in dogs. Shock 2003; 19: 289-296.

25. Gennari R, Alexander JW, Boyce ST, Lilly N, Babcock GF, Cornaggia M. Effects of the angiotensin converting enzyme inhibitor enalapril on bacterial translocation after thermal injury and bacterial challenge. Shock 1996; 6: 95-100.

26. Morton JJ, Semple PF, Ledingham IM, Stuart B, Tehrani MA, Garcia $A R$, et al. Effect of angiotensin-converting enzyme inhibitor (SQ 20881) on the plasma concentration of angiotensin I, angiotensin II, and arginine vasopressin in the dog during hemorrhagic shock. Circ Res 1977; 41: 301-308.

27. Kincaid EH, Miller PR, Meredith JW, Chang MC. Enalaprilat improves gut perfusion in critically injured patients. Shock 1998; 9: 79 83.

28. Wiel E, Pu Q, Leclerc J, Corseaux D, Bordet R, Lund N, et al. Effects of the angiotensin-converting enzyme inhibitor perindopril on endothelial injury and hemostasis in rabbit endotoxic shock. Intensive Care Med 2004; 30: 1652-1659.

29. Wall P, Buising C, Henderson L, Rickers T, Cardenas A, Owens L, et al. Enalaprilat improves systemic cardiovascular parameters and mesenteric blood flow during hypotensive resuscitation from hemorrhagic shock in dogs. Shock 2002; 17: 228-233.

30. Tadros T, Traber DL, Heggers JP, Herndon DN. Angiotensin II inhibitor DuP753 attenuates burn- and endotoxin-induced gut ischemia, lipid peroxidation, mucosal permeability, and bacterial translocation. Ann Surg 2000; 231: 566-576.

31. Garrido A, Poli de Figueiredo L, Rocha e Silva M. Experimental models of sepsis and septic shock: an overview. Acta Cir Bras 2004; 19: $82-88$ 